\title{
LIABILITY REGIME OF ONLINE PLATFORMS NEW APPROACHES AND PERSPECTIVES*
}

\author{
Laura Rózenfeldová, LLM, Phd Candidate \\ Pavol Jozef Šafárik University in Košice, Faculty of Law \\ Kováčska 26, Košice, Slovakia \\ laura.rozenfeldova@student.upjs.sk
}

\author{
Pavol Sokol, PhD \\ Pavol Jozef Šafárik University in Košice, Faculty of Science \\ Šrobárova 2, Košice, Slovakia \\ pavol.sokol@upjs.sk
}

\begin{abstract}
Collaborative economy creates new business models in different sectors of the economy and produces new impulses for the development and innovations in the traditional areas. However, to answer the new questions arising from this segment of the economy, we must consider the existing legal framework regarding the central subjects of the collaborative economy - online platforms. In this paper we examine one legal aspect of particular relevance in this regard, specifically the liability of online platforms for content that they host. In particular, we consider the existing liability regime of these platforms, new proposals approved by the European Parliament and we conclude this paper with the critical examination of the liability regime in relation to the push for the adoption of voluntary proactive measures on the EU level.
\end{abstract}

Keywords: online platforms, liability, hosting, illegal content online, copyright

\section{INTRODUCTION}

The Digital Single Market Strategy for Europe defines as one of its objectives the fight against illegal content online. In general, this notion of digital piracy is defined as "the act of reproducing, using, or distributing information products, in digital formats andlor using digital technologies, without the authorization of their legal owners." It is recognized that the most relevant subjects intermediating access

This paper is funded by the Slovak APVV project under contract No. APVV-14-0598 and by the APVV project under contract No. APVV-17-0561

1 Belleflamme, P.; Peitz, M., Digital piracy, Springer New York, 2014 
to content online or the "key gatekeepers of the internet" are online platforms. As the Commission states, "the principle, enshrined in the e-Commerce Directive, that Internet intermediary service providers should not be liable for the content that they transmit, store or host, as long as they act in a strictly passive manner has underpinned the development of the Internet in Europe." ${ }^{3}$ At the same time, if illegal content is identified, the relevant subjects are required to act to remove or disable access to such content. However, the process of removal or of disabling access to illegal content online is not without its flaws - it can be slow, ineffective, lacking transparency and a uniform approach within the European Union.

One of the types of illegal content often made available on the internet without the authorization of the relevant right-holders is content that infringes intellectual property rights, such as copyright. Despite of some efforts on the national level, no uniform approach on how to prevent the upload of protected subject-matter or the process of its subsequent removal or disabling of access to it after its provision online has been established. The absence of a uniform approach as well as the increased relevance of this issue in recent years (as presented by the Commission that included fight against illegal content online in the II. Pillar of its Digital Single Market Strategy for Europe) are reasons why the authors of this paper decided to examine this issue more closely.

To formalize the scope of our work, two research questions are stated:

a) How proactive measures can be implemented by online platforms?

b) What changes brings the new Article 17 of the proposed Directive on copyright in the Digital Single Market?

This paper is organised into five sections. Section 1 provides a brief definition of the term 'online platforms'. Section 2 examines the existing liability regime of online platforms, specifically focusing on the interpretation of one of the liability exemptions - hosting. The following Section 3 outlines the activities of the Commission in this area in recent years. Section 4 discusses the adoption of proactive voluntary measures by online platforms. The last Section analyses Article 17 of the Copyright proposal and the relevant changes it proposes.

2 Communication from the Commission on the Mid-Term Review of the implementation of the Digital Single Market Strategy. A Connected Digital Single Market for All. COM (2017) 228 final

3 Communication from the Commission. A Digital Single Market Strategy for Europe. COM/2015/0192 final 


\section{ONLINE PLATFORMS}

To explain what online platforms are and to provide their definition is not an easy task. Definitions of online platforms that exist in an academic literature differ in various aspects. A uniform definition of online platforms currently does not exist, as there is no consensus among professionals or legislators, as to what such definition should include.

One of the more general definitions describes online platforms as "all online spaces where users engage in commercial and non-commercial interaction with each other." ${ }^{4}$ As a stipulation of a single definition is not suitable or necessary, the European Commission refers in its works to a general enumeration of the most common characteristics of online platforms:

a) capacity to facilitate, and extract value, from direct interactions or transactions between users; Platforms may provide access to goods, services or information resulting in the digital value creation, "notably by capturing significant value (including through data accumulation), facilitating new business ventures, and creating new strategic dependencies." 5

b) ability to collect, use and process a large amount of personal as well as nonpersonal data in order to optimize, inter alia, the service and experience of each user.

c) capacity to build networks, where any additional user will enhance the experience of all of the existing users (the so-called 'network effect');

d) ability to create and shape new markets and to regulate or control the access to them;

This challenges the existing traditional markets and drives innovation, growth and competition in the digital economy. Particularly significant is the fact that platforms enable small and medium-sized enterprises to participate on markets they would not otherwise be able to reach in the traditional business setting and enable the creation of "new forms of participation or conducting business based on collecting, processing, and editing large amount of data."

Gillespie, T., The Politics of 'Platforms', New Media \& Society, 2010, Vol. 12, No. 3, ISSN: 1461-4448, pp. 347-364

5 Communication from the Commission. Online Platforms and the Digital Single Market. Opportuni-

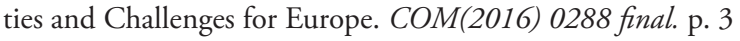

$6 \quad$ Ibid., p. 2 


\section{a) reliance on information and communications technologies. ${ }^{7}$}

Facilitating and supporting the creation of online platforms is an economic and strategic imperative for Europe in the context of the Digital Single Market formation. Currently the EU represents only $4 \%$ of the total market capitalisation of the largest online platforms, as the vast majority of them originate in the US and Asia. ${ }^{8}$ To change this course, the Commission has determined various steps to be taken in order to assist in and encourage the development of a platformbased economy in the EU. Firstly, it is necessary to eliminate the legal uncertainty resulting from the existence of different rules governing platforms in individual Member States in relevant areas. Despite of the fact that full harmonisation is not possible or even desired, it is necessary with regard to certain issues, for instance in the area of the personal data protection (currently regulated by the newly adopted General Data Protection Regulation). However, as the Commission states, if the adoption of a new legislation is necessary, it should "only address clearly identified problems relating to a specific type or activity of online platforms in line with better regulation principles" - the so-called 'problem-driven approach'. Furthermore, it is necessary to ensure the online platforms' conformity with the existing EU rules, e. g. with regard to the competition, consumer protection, and protection of freedoms of internal market. Finally, "principles-based self-regulatory measures, including industry tools for ensuring application of legal requirements and appropriate monitoring mechanisms" 10 play a certain role. To summarize, the Commission has introduced the following principles necessary to consider, when responding to issues associated with online platforms:

a) "a level playing field for comparable digital services;

b) responsible behaviour of online platforms to protect core values;

c) transparency and fairness for maintaining user trust and safeguarding innovation;

d) open and non-discriminatory markets in data-driven economy." 11

\footnotetext{
7 Commission Staff Working Document Online Platforms Accompanying the document Communication on Online Platforms and the Digital Single Market. SWD/2016/0172 final. p. 2

8 Communication from the Commission. Online Platforms and the Digital Single Market. Opportunities and Challenges for Europe. COM(2016) 0288 final, p. 3

$9 \quad$ Ibid., p. 5

10 Ibid.

11 Ibid.
} 


\section{THE LIABILITY REGIME OF ONLINE PLATFORMS}

The legal framework regarding the liability of online platforms is contained in the Directive 2000/31/EC of the European Parliament and of the Council of 8 June 2000 on certain legal aspects of information society services, in particular electronic commerce, in the Internal Market (Directive on electronic commerce) (hereinafter only as "ECD”). ECD aims to create a legal framework, within which the free movement of information society services between individual Member States is ensured through the elimination of existing barriers.

The liability regime stipulated in ECD pertains to the so-called intermediary service providers defined as any subjects (natural or legal persons) providing an information society service. The definition of information society service is contained in another legislative act characterising it as "any service normally provided for remuneration, at a distance, by electronic means and at the individual request of a recipient of service." 12

ECD distinguishes three different liability regimes concerning specific activities of service providers - mere conduit, caching and hosting, each of them stipulating specific conditions for the application of the liability exemption aiming to restrict situations, in which intermediary service providers may be held liable pursuant to the applicable national law. The liability exemptions are established in a horizontal manner covering civil, criminal and administrative liability regarding all types of illegal activities initiated by third parties online, including copyright and trademark piracy, unfair commercial practices, misleading advertising, etc. ${ }^{13}$ As this paper focuses on the issue of illegal content online, one of the above mentioned exemptions is of particular importance in this regard and therefore will be closely examined.

\subsection{Hosting exemption and its interpretation by the CJEU}

Hosting relates to the provision of information society service consisting of the storage of information provided by a recipient of the service. In this case, the service provider shall not be liable for the information stored at the request of the recipient of the service, if these conditions are fulfilled:

12 Article 1 (b) of the Directive (EU) 2015/1535 of the European Parliament and of the Council of 9 September 2015 laying down a procedure for the provision of information in the field of technical regulations and of rules in Information Society services (codification) OJ L 241, 17.9.2015, p. 1-15

13 Verbiest, T.; Spindler, G.; Riccio, G. M., Study on the liability of internet intermediaries, Available at SSRN 2575069, 2007.p. 4 
a) "the provider does not have actual knowledge of illegal activity or information and, as regards claims for damages, is not aware offacts or circumstances from which the illegal activity or information is apparent; or

b) the provider upon obtaining such knowledge or awareness, acts expeditiously to remove or to disable access to the information." 14

Various implementation issues resulted from the application of the liability exemption stipulated in Article 14 (1) ECD. The Court of Justice (hereinafter only as "CJEU") has provided its interpretation of the service provider's liability in various cases. In the case C-324/09 L'Oréal and Others, specifically with regard to the operator of an online marketplace (eBay), the CJEU analysed the question, whether the service provided by the operator of an online marketplace is covered by Article 14 (1) ECD, and, if so, under which circumstances it may be concluded that the operator of an online marketplace has 'awareness' within the meaning of Article 14 (1) ECD. Another relevant interpretation is contained in the joined cases C-236/08 to C-238/08 Google France and Google, where the CJEU examined, whether an internet referencing service, that provides storage of information supplied by the advertiser, is exempted from the liability and therefore cannot be held liable prior to it being informed of the unlawful conduct of the advertiser. Conclusions of the CJEU in the above mentioned cases can be summarized into conditions that need to be fulfilled in order for the liability exemption stipulated in Article 14 (1) ECD to be applicable.

First of all, provision of an information society service within the meaning of ECD. In both cases the CJEU has concluded, that services provided feature all of the elements of the information society service definition. It must be noted that in most cases, an examination on a case-by-case basis will be necessary to determine whether activities of a certain provider can be considered as 'the provision of information society service'. To illustrate, the CJEU stated that a service consisting of facilitating relations between sellers and buyers of goods is, in principal, considered a service for the purposes of ECD. ${ }^{15}$

Second of all, storage of information. In both of the above mentioned cases it was confirmed by the CJEU that the relevant service providers stored information provided to them. As stated in the case C-324/09, eBay's activities include, inter

14 Article 14 (1) of the Directive 2000/31/EC of the European Parliament and of the Council of 8 June 2000 on certain legal aspects of information society services, in particular electronic commerce, in the Internal Market (Directive on electronic commerce) OJ L 178, 17.7.2000, p. 1-16

15 See also the interpretation of the term 'information society service' provided in: Harrington, J., Information society services: information society services: what are they and how relevant is the definition?, Computer Law \& Security Review, Vol. 17, No. 3, 2001, p.174-181 
alia, the storage of data supplied by its customers and sellers, and "the storage operation is carried out by eBay each time that a customer opens a selling account with it and provides it with data concerning its offers for sale." 16 Similarly, in the joined cases C-236/08 to C-238/08, the referencing service provider "transmits information from the recipient of that service, namely the advertiser, over a communications network accessible to internet users and stores, (...), certain data, such as the keywords selected by the advertiser, the advertising link and the accompanying commercial message, as well as the address of the advertiser's site." ${ }^{17}$ However, it must be noted, that the mere storage of information is not considered sufficient for concluding that a certain service falls within the scope of Article 14 (1) ECD. The CJEU therefore requires a more detailed examination: "that provision must, in fact, be interpreted in the light not only of its wording but also of the context in which it occurs, and the objectives pursued by the rules of which it is part." ${ }^{18}$

Third of all, the internet service provider's conduct is limited to that of an intermediary provider within the meaning of ECD.

Another condition is that a service provider provides a service neutrally, by a merely technical, automatic and passive processing of the data provided by its customers, and does not play an active role of such kind as to give it knowledge of, or control over, those data. ${ }^{19}$ Certain activities of the service provider, such as a storage of offers for sale on its servers, setting the terms of its service, remuneration for such service and provision of general information to its customers, are not sufficient for denying the service provider the liability exemption. However, if the service provider's activities also include the provision of assistance, for instance by optimizing the presentation of the offers for sale in question, or by promoting those offers, than the service provider can no longer be considered as neutral, but as one playing an active role of such a kind that gives it knowledge of, or control over, the data relating to those offers for sale. To illustrate, if a service provider, after processing the data provided to it by its advertisers, determines how and in what order will their ads be displayed, it has control over such data and therefore will no longer benefit from the liability exemption.

Furthermore, the absence of actual knowledge or awareness. Another condition is that the service provider has not had 'actual knowledge' of illegal activity or information, and, as regards claims for damages, has not been aware of facts or circumstances from which the illegal activity or information is apparent. The condition

16 Case C-324/09 L'Oréal and Others [2011], ECLI:EU:C:2011:474, p. 110

17 Joined cases C-236/08 to C-238/08 Google France and Google [2010],ECLI:EU:C:2010:159, p. 111

18 Case C-324/09 L'Oréal and Others [2011], ECLI:EU:C:2011:474, p. 111

19 Joined cases C-236/08 to C-238/08 Google France and Google [2010],ECLI:EU:C:2010:159, p. 114 
continues in stipulating, that if the service provider obtains such knowledge or awareness, it is obligated to act expeditiously to remove, or disable access to, the information. The CJEU therefore states, that the service provider will not be entitled to the exemption liability, if it is aware of facts or circumstances "on the basis of which a diligent economic operator should have identified the illegality in question and acted in accordance with Article 14 (1)." 20 The obligation of the service provider covers every situation, in which it becomes aware, in one way or another, of such facts or circumstances, whether as a result of an investigation undertaken on its own initiative or through a notification by a third party (e. g. trusted flaggers, rightholders, etc.).

It must also be mentioned that the subject of the above examined cases was not the infringement of copyright, but the infringement of trademarks. Due to this and despite of the interpretation provided by the CJEU, various issues still remain unsettled. Examination on a case by case basis with regard to the specific circumstances of each case is therefore necessary. This creates problems and legal uncertainty for the individual service providers with regard to how to continue their operations, when it may not be clear, whether the liability exemption in question applies to them or not.

\section{RECENT ACTIVITIES OF THE COMMISSION}

The liability exemptions stipulated in ECD have significantly influenced the development of online platforms and their activities in Europe. As the Commission stated, "it is not always easy to define the limits on what intermediaries can do with the content that they transmit, store or host before losing the possibility to benefit from the exemptions from liability." 21 The Commission recognizes the need to address certain issues resulting from the online platform's operations, one of which is the fact that the amount of digital content available on the internet grows extensively and includes inter alia illegal content. The detection and the subsequent removal of illegal content presents an urgent challenge that needs to be addressed. Due to this, the fight against illegal content online has been included in the II. pillar of the Digital Single Market Strategy as one of the key issues requiring closer examination. The Commission stated two principles to be applied when addressing online platforms in this matter:

\footnotetext{
20 Case C-324/09 L'Oréal and Others [2011], ECLI:EU:C:2011:474, p. 120

21 Communication from the Commission. A Digital Single Market Strategy for Europe COM/2015/0192 final, p. 12
} 
a) maintaining a balanced and predictable liability regime for online platforms and

b) pursuing a sectoral, problem-driven approach in tackling illegal content online.

These principles are applied in the Commission's Communication on Tackling Illegal Content Online ${ }^{22}$ and the recently adopted Commission Recommendation on measures to effectively tackle illegal content online ${ }^{23}$ (hereinafter only as "Recommendations").

\section{PUSH FOR THE ADOPTION OF VOLUNTARY MEASURES BY ONLINE PLATFORMS}

One of the new approaches regarding the fight against illegal content online that can be identified in recent years is the Commission's 'push' for the adoption of voluntary proactive measures by platforms in their own capacity. The objective of this recommendation is to gain knowledge or awareness of potentially illegal content to which platforms provide access to.

To eliminate possible concerns in this regard, the Commission expressly specified that "taking such voluntary proactive measures does not automatically lead to the online platform losing the benefit of the liability exemption." 24 This follows the CJEU's interpretation of Article 14 ECD that clarified, that the mere fact that the providers' activities are diverse and not only focused on the intermediation (e. g. including determining its terms of service, obtaining remuneration for such services, provision of general information to its customers etc.), ${ }^{25}$ does not have a direct effect of denying it the liability exemption, as it "does not necessarily mean that it plays an active role in respect of the individual content items it stores." 26 Therefore, these concerns should not preclude the application of the necessary proactive measures by the relevant providers, as they have a relevance to them, e. g. to enforce their terms of service. As the Commission has noted, "many large platforms are now making use of some form of matching algorithms, based on a range of technologies,

22 Communication from the Commission. Tackling Illegal Content Online Towards an enhanced responsibility of online platforms COM (2017) 555 final

23 Commission Recommendation of 1.3 .2018 on measures to effectively tackle illegal content online (C(2018) 1177 final)

24 Communication from the Commission. Tackling Illegal Content Online. Towards an enhanced responsibility of online platforms. $\operatorname{COM}(2017) 555$ final, p. 10

25 See: Case C-324/09 L'Oréal and Others [2011], ECLI:EU:C:2011:474, p. 115-116

26 Communication from the Commission. Tackling Illegal Content Online. Towards an enhanced responsibility of online platforms. $\operatorname{COM(2017)} 555$ final, p. 11 
from simple metadata filtering, to hashing and fingerprinting content ${ }^{27}$ aimed at the automated content recognition.

The Commission encourages providers "to take, where appropriate, proportionate and specific proactive measures in respect of illegal content. Such proactive measures could involve the use of automated means for the detection of illegal content only where appropriate and proportionate and subject to effective and appropriate safeguards." 28

An important term in this respect is the term 'proactive measure'. In general, it is a measure adopted to solve a problem before it occurs. Proactive model consists of four elements: ${ }^{29}$

a) responsibility - proactive measures shift the responsibility away from the individual claimant to the provider, which is in a position to take action to eliminate unlawful conduct;

b) participation - given the potential 'top-down' nature of proactive measures, it is important to involve all stakeholders, such as providers, copyright holders, potential victims etc. in the process;

c) monitoring - unlike a proactive model, which is concerned with a selfcontained incident, proactive measures are programmatic and on-going. A process of monitoring and review is therefore essential to assess whether a proactive measure is effective;

d) enforcement and compliance - a key challenge for proactive measures, therefore, is to devise appropriate means of enforcement. In this respect, principles founded on the concept of equity are important. Arbitration courts considering this principle may be a possible solution. ${ }^{30}$

An important aspect to consider is the time of the adoption of these measures. From the above-mentioned technical perspective, proactive measures are measures adopted before the incident (e. g. the infringement of copyright) occurs. The question therefore is, when the proactive measures shall be applied - before the upload of such a content or after it is made available to the public. To illustrate, considering one of the measures used in practice by providers - the measure of the 'fingerprint creation' (the creation of a database with 'fingerprints' or samples of the

\footnotetext{
$27 \quad$ Ibid., p. 12

28 Article 18 Commission Recommendation of 1 . March 2018 on measures to effectively tackle illegal content online. C(2018) 1177 final, p. 12

29 Fredman, S., Making Equality Effective: The role of proactive measures, 2009

30 Suchoža, J.; Hučková, R., Reflections on Arbitration Proceedings, in: The Relationship between Constitutional Values, Human Rights and Arbitration, New York: JurisNet, LLC, 2011, pp. 161-180
} 
protected content against which the uploaded content is compared to), the upload of the content and the provision of a 'fingerprint' is necessary. It follows that proactive measures should be carried out immediately after the item is in the provider's sphere, at the latest, before it can be used (e.g. to share with the public).

Different factors have to be considered to determine, whether the adoption of certain measures is appropriate, e. g. if the content's illegality has already been established, if the contextualization with regard to a certain type of content is not essential, the nature, scale and purpose of the envisaged measures, the type of content, the content's notification by law enforcement agencies, if action had already been taken, etc. ${ }^{31}$ Moreover, it is necessary to establish specific safeguards to ensure that:

a) providers act in a diligent and proportionate manner in respect of content stored by them, in particular when processing notices and counternotices and when deciding on the possible removal or disabling of access to allegedly illegal content, and

b) decisions concerning such content, in particular regarding the removal or disabling access to it, are accurate and well founded. The latter can be ensured through human oversight and verifications that may be needed in certain cases to determine the illegality of content at issue. Therefore, different safeguards should be established not only by applicable law (e. g. regarding privacy and personal data protection), but also by providers themselves as additional safeguards aiming to avoid e. g. the removal of legal content.

One example of a possible and currently used proactive measure is the Content ID, 32 which is based on a digital fingerprinting ${ }^{33}$ system developed by Google to protect copyright holders. ${ }^{34}$ Its purpose is to identify and manage the content on the

31 Article 18 Commission Recommendation of 1 . March 2018 on measures to effectively tackle illegal content online. (2018) 1177 final p. 12. Preamble (25)

32 YouTube Content ID Service. 2018, [https://developers.google.com/apps-script/advanced/youtube-content-id] Accessed 27.03.2019

33 According to Broder, fingerprints are short tags for larger objects. An example of a large object is a video file. As comparing two large files would take a relatively long time, it is preferable to compare shorter strings (tags) that clearly represent them. See also: Broder, A. Z. Some applications of Rabin's fingerprinting method, in: Sequences II. Springer, New York, NY, 1993, p. 143-152

34 This system is only available to the right holders holding exclusive rights to the copyrighted content, on a certain territory (if they do not hold a worldwide license) and after evaluation of their actual need for this tool. In certain cases different tools may be more suitable for rightholders, such as copyright notification web form or Content Verification Programme 
Google's platform YouTube. ${ }^{35}$ The first necessary step is that the rightholders provide YouTube with audio or visual reference files identifying their works, which are then included in a database that creates a specific 'fingerprint' from those files. The Content ID system then scans videos on YouTube against these fingerprints. If a match is found, the rightholders have three options - to block the video from being viewed, to monetize it by running ads against it (in some cases revenues are shared with the uploader) or to track the viewer data for detailed analytics (e. g. in which countries is the video popular). As YouTube states, the second option of monetizing the video is the most popular among rightholders, who then do not have to rely on the notice and take-down procedure also available in the case of copyright infringement.

Another similar measure is the system used by SoundCloud. ${ }^{36}$ Like YouTube, SoundCloud has already implemented its own system for identifying copyrightprotected content based on the acoustic fingerprinting. ${ }^{37}$ Difference between these measures is in the primary input provided by copyright holders (e.g. audio signal, raw data), which is entered to the fingerprinting algorithm.

Creating a fingerprint and comparing it to a local service database is the first step in the copyright protection. However, it is not without its flaws. The disadvantage of local fingerprinting databases is that they do not contain fingerprints of all of the copyright-protected content. It is likely that the content uploaded will be considered as legitimate since its fingerprint is not yet contained in the database. The possible solution may present the use of the global copyright context database such as the ZEFR's rights management service ${ }^{38}$ called RightsID. This system is widely used by global content companies (e.g. Universal, Paramount, MTV, Facebook). In addition to various machine learning methods, ZEFR also uses human review, which reduces the possibility of a wrong decision, but also increases the time needed for the necessary comparison.

\section{CHANGES PROPOSED IN THE DIRECTIVE ON COPYRIGHT IN THE DIGITAL SINGLE MARKET}

The newly formulated Article 17 of the Directive on copyright in the Digital Single Market (hereinafter only as "Directive") proposes a new approach to the li-

35 See also: Letai, P., Is You Tube a copyright infringer? The liability of Internet hosting providers under Spanish Law, The Liability of Internet Hosting Providers Under Spanish Law, February 3, 2012

36 Soundcloud. 2019, [https://soundcloud.com/] Accessed 27.03.2019

37 An acoustic fingerprinting is a type of fingerprinting algorithm, which output is generated from an audio signal and can be used to identify an audio sample in an audio database. For more details, see Wang, A. et al., An Industrial Strength Audio Search Algorithm, in: Ismir, 2003, p. 7-13

38 Zefr's right management. 2019, [https://zefr.com/about-us/rights-management] Accessed 27.03.2019 
ability of online platforms. In this section, we provide a short overview of the most relevant changes it contains and their brief examination. It must be noted, that this Directive is not applicable inter alia to sharing platforms. Despite of this, it establishes a new and challenging approach to the examined subject and therefore will be briefly analysed.

\subsection{Scope of the Directive}

Article 1 (1) of the Directive defines its scope as stipulating rules on the further harmonisation of EU law "applicable to copyright and related rights in the framework of the internal market, taking into account, in particular, digital and cross-border uses of protected content." 39

The second Chapter of the Directive focuses on certain uses of protected content by online services, specifically the use of protected content by online contentsharing service providers. These providers enable third parties (their users) to upload content which is then stored on their servers. In this case, the Article 14 ECD should be applicable, if the stipulated conditions are met. The problem arises, however, when firstly, the uploaded content is protected content (under copyright or other intellectual property rights), secondly, when providers give access to such content to other subjects, therefore communicating it or making it available to the public, and lastly, when no prior authorisation from the relevant rightholders has been granted. In this regard, "legal uncertainty exists as to whether the providers of such services engage in copyright-relevant acts, and need to obtain authorisation from rightholders for content uploaded by their users who do not hold the relevant rights in the uploaded content, without prejudice to the application of exceptions and limitations provided for in Union law." ${ }^{40}$

To eliminate this legal uncertainty, the proposed Directive stipulates new obligations for online content-sharing service providers (hereinafter only as "providers") which provide services that "play an important role on the online content market by competing with other online content services, such as online audio and video streaming services, for the same audiences." 41 This Directive therefore regulates services, "the main or one of the main purposes of which is to store and enable users to upload and share a large amount of copyright-protected content with the purpose of obtaining profit therefrom, either directly or indirectly, by organising it and promoting it in order to attract a larger audience, including by categorising it and using targeted promotion

Article 1 (1) of the proposed Directive on copyright in the Digital Single Market

$40 \quad$ Ibid., Recital 61

$41 \quad$ Ibid., Recital 62 
within it. Such services should not include services that have a main purpose other than that of enabling users to upload and share a large amount of copyright-protected content with the purpose of obtaining profit from that activity." 42 Other services that do not meet the above stated conditions are outside the scope of this Directive.

\subsection{Act of communication to the public}

The 'act of communication' was defined by the CJEU as "any transmission of the protected works, irrespective of the technical means of process used [where] every transmission or retransmission of a work which uses a specific technical means must, as a rule, be individually authorized." ${ }^{33}$ Moreover, as is apparent from the wording of Article 3 (1) of the InfoSoc Directive ${ }^{44}$, it is sufficient that a work is made available to the public, irrespective of whether it is actually accessed or not.

Various examples fulfilling the requirements of the 'act of communication' concept have been provided by the CJEU in its decisions, such as the provision of clickable links on a website leading to protected works published without any restrictions on another website, ${ }^{45}$ or the making available and managing of an online sharing platform, on which copyright protected works are made available through the use of the BitTorrent protocol. ${ }^{46}$

One of the relevant factors considered in these cases was the indispensable role of a user and the deliberate nature of its intervention. According to the settled case law, the user makes an act of communication when "it intervenes, in full knowledge of the consequences of its action, to give access to a protected work to its customers, and does so, in particular, where, in the absence of that intervention, its customers would not, in principle, be able to enjoy the broadcast work." ${ }^{77}$

In the latter case the CJEU examined the question of whether the concept of 'communication to the public' includes the making available and management of an online sharing platform which, by means of indexing metadata relating to copyright protected works, enables the platform's users to locate these works and

\footnotetext{
$42 \quad$ Ibid., Recital 62

43 Judgement of the Court of 19 November 2015, C-325/14 SBS Belgium, ECLI:EU:C:2015:764, pp. 16,17

44 Directive 2001/29/EC of the European Parliament and of the Council of 22 May 2001 on the harmonisation of certain aspects of copyright and related right in the information society. OJ L 167, 22.6.2001, p. $10-19$

45 See Judgement of the Court of 26 April 2017, C-527/15 Stiching Brein, ECLI:EU:C:2017:456

46 See Judgement of the Court of 14 June 2017, C-610/15 Stiching Brein, ECLI:EU:C:2017:300, p. 37

47 Ibid., p. 35
} 
to share them in the context of a peer-to-peer network..$^{48}$ The liability of these websites' operators have been examined by the CJEU in the case C-610/15 Stiching Brein. The CJEU stated that "as a rule, any act by which a user, with full knowledge of the relevant facts, provides its clients with access to protected works is liable to constitute an 'act of communication'." ${ }^{49}$ The Court considered following factors as relevant to the establishment of a communication of a work:

a) the platform provided access to copyright protected works to its users without the authorisation of the relevant rightholders;

b) these works could be accessed by the platform's users at any time or place;

c) despite of the fact that such works have not been provided by the platform itself, but by its users, this would not be possible without the existence of such a platform, or at the very least sharing of such works would prove to be more complex;

d) the platform by indexing torrent files allowed its users to locate these works, using for example its search engine;

e) the platform also indexed the works shared under different categories (relevance, genre, popularity) and obsolete of faulty torrent files have been deleted by the platform and some content have been actively filtered, which rebuts the assumption that the platform only provided physical facilities for enabling or making a communication.

After examining all of these factors the Court's conclusion was that "the making available and management of an online sharing platform (...) must be considered to be an act of communication for the purposes of Article 3 (1) of Directive 2001/29." 50

48 In general, a peer-to-peer network (P2P) is described as a network, in which two or more computers communicate with each other without the need of a central server to enable such communication (decentralized system). Various protocols make use of the peer-to-peer network, one of which is the BitTorrent protocol used to share files between its users (peers). The basic feature of the BitTorrent protocol is that it does not create a central server, from which files would be downloaded, but it divides a file into segments which are then downloaded by its users (leechers) from other users' computers in a network enabling such download (seeders). When the user wants to download a file, he/she must first download the relevant torrent file and open it with a specific software, namely the 'BitTorrent Client'. Various websites are created to enable the download of such torrents, predominantly relating to copyright protected works without any authorization from the relevant rightholders

49 Judgement of the Court of 14 June 2017, C-610/15 Stiching Brein, ECLI:EU:C:2017:300, p. 34

50 Ibid., p. 39 
These cases demonstrate the need for a broad interpretation of the term 'act of communication' to ensure the fulfilment of the InfoSoc Directive's objective, which is to establish a high level of protection of the relevant copyright-holders. However, another requirement must be examined before granting such protection, namely that a work has been communicated to a public.

\subsection{Act of making available to the public}

The term 'public' is defined in the CJEU's case law as referring to "an indeterminate number of potential recipients and implies, moreover, a fairly large number of persons." ${ }^{11}$ If a work is communicated only to a specific group of individuals, or a certain de minimis threshold is not reached, it is not communicated to the public. According to the settled case law, to be categorized as a 'communication to the public', "a protected work must be communicated using specific technical means, different from those previously used or, failing that, to a 'new public', that is to say, to a public that was not already taken into account by the copyright holders when they authorized the initial communication to the public." 52

To illustrate, the Court in the case C-610/15 Stiching Brein examined, whether an online sharing platform, on which protected works have been made available to its users through the use of torrents, communicated these works to the public. The Court considered as relevant the number of the platform's users (its operators claiming to have several dozens of millions of 'peers'), and stated that "in this respect, the communication at issue (...) covers, at the very least, all of the platform's users," ${ }^{3}$ which can access such works at any time and place, therefore aiming at an indeterminate number of potential recipients. Moreover, it was necessary to determine whether such communication was aimed at a 'new public'. This was confirmed, as the Court held that the platform's operators could not be unaware that the platform in question provided access to works without the authorization from the relevant rightholders, as they expressly stated their purpose to enable the platform's users' to access such works and encouraged them to make copies of those works.

This interpretation of the author's right to prohibit communication of his/her work to the public has been considered as creating an "extremely expansive right," 54 without legal certainty as to which conduct will fulfil the conditions of this right's

51 Judgement of the Court of 7 December 2006, C-306/05 SGAE, ECLI:EU:C:2006:764, pp. 37, 38

52 Judgement of the Court of 26 April 2017, C-527/15 Stiching Brein, ECLI:EU:C:2017:300, p. 33

53 Judgement of the Court of 14 June 2017, C-610/15 Stiching Brein, ECLI:EU:C:2017:300, p. 42

54 Groom, J., The Pirate Bay: CJEU rules that operating a torrent file indexing site is a communication to the public. Journal of Intellectual Property Law \& Practice, Vol. 12, No. 12, 2017, p. 965-968 
two components, as both of the previously examined cases focusing on very specific issues show. Therefore a right balance will have to be found between ensuring the high protection of copyright holders and other concerned parties, particularly with regard to businesses (freedom to conduct a business) and individual users (freedom of expression and information).

\subsection{The new concept in the Directive}

The Directive establishes a new understanding of the terms examined in the chapters above. Specifically, Article 17 (1) stipulates an obligation of Member States to "provide that an online content-sharing service provider performs an act of communication to the public or an act of making available to the public for the purposes of this Directive when it gives the public access to copyright-protected works or other protected subject matter uploaded by its users." In such a case, the provider in question is required to obtain the necessary authorisation from the rightholders, e. g. a licensing agreement, to communicate or to make available to the public the protected content.

An important rule is contained in Article 17 (3), which stipulates that when service providers perform an act of communication or of making available to the public under the conditions laid down in this Directive, "the limitation of liability established in Article 14 (1) of Directive 2000/31/EC shall not apply to the situations covered by this Article." This provision effectively determines the relationship between this Directive and the eCommerce Directive, excluding the applicability of the hosting exemption as regards the provision of services which are within the scope of this Directive. This supports the latest approaches of the legislator to the liability of online platforms, where the objectives are to maintain a balanced and predictable liability regime and to pursue a sectoral, problem-driven approach in tackling illegal content online. The legislator, therefore, effectively limits the scope of the eCommerce Directive, specifically excluding the provision of access to copyright-protected or other protected subject matter from the hosting exemption, and therefore creates a specific liability regime for cases in which no authorisation has been granted by the relevant rightholders.

This approach inter alia answers one of the issues related to the applicability of the hosting exemption, namely the fairly extensive scope of the protection it provides. In this regard, providers are in general not liable for any content that they store until they learn of its illegality. This was contested in the case of platforms that predominantly store copyright-protected content without the consent of the rightholders and profit from this service. In this regard, the Recital 62 specifically states that "in order to ensure a high level of copyright protection, the liability exemp- 
tion mechanism provided for in this Directive should not apply to service providers the main purpose of which is to engage in or to facilitate copyright piracy." 55 This includes e. g. platforms operating on a peer-to-peer basis enabling their users to download the content in question through the use of torrents.

Other changes as regards the liability of a provider can be identified in the Directive, but due to the scope of this paper we will only briefly present these changes. The Directive considers as necessary the cooperation between the providers and the rightholders, established through the provision of information between these subjects regarding the process of removal or of disabling of access to illegal content, e. g. through the notification system. Moreover, it is required that a general monitoring obligation is not imposed, as this would contradict Article 15 ECD. Furthermore, the prevention of over-removal of non-infringing content and therefore the protection of freedom of information must be ensured. It is therefore necessary to strike a balance between competing fundamental rights, including but not limited to the right to the personal data protection, freedom to receive and impart information included in the freedom of expression, freedom to conduct business, right to the protection of intellectual property etc.

\section{Related works}

Colangelo and Maggiolino consider the EU initiatives to resolve the reported value gap between the rightholders and online platforms, critically assessing the Commission's Proposal for a directive on copyright within the digital single market, specifically focusing on its consistency with the CJEU's interpretation of the term 'communication to the public' and with the liability exemptions established by the eCommerce Directive, as well as arguing the lack of empirical evidence supporting the need for such legislation. ${ }^{56}$ Frosio provides a criticism of the EU's new approaches as regards the existing safe harbours established in the eCommerce Directive in numerous papers, also arguing the lack of empirical evidence supporting such recourse. ${ }^{57}$ The former Article 13 of the proposed Directive on copyright is further discussed by Romero-Moreno, assessing the compatibility of content recognition and filtering technology with the rights and freedoms of the

\footnotetext{
55 Recital 62 of the proposed Directive on copyright in the Digital Single Market

56 See: Colangelo, G.; Maggiolino, M., ISPs' copyright liability in the EU digital single market strategy. International Journal of Law and Information Technology, Vol. 26, No. 2, 2018, p. 142-159

57 See: Frosio, G. F., Reforming intermediary liability in the platform economy: a European digital single market strategy. Nw. UL Rev. Online, 2017
} 
concerned parties..$^{58}$ The afore-mentioned Article 13 and its shortcomings has also been discussed by Senftleben et al. ${ }^{59}$

\section{CONCLUSION}

The existence of online platforms is considered as an economic and strategic imperative for Europe. Due to this, their establishment and functioning has been promoted inter alia by the creation of the specific liability regime which enables platforms to provide their information society services without automatically becoming liable if and when protected subject-matter is made available through their services, considering the amount of content continuously uploaded on the internet by their users that cannot be effectively and in a timely manner controlled at the time of its provision. However, to ensure the protection of fundamental rights within the digital environment, the EU requires from online platforms responsible behavior aimed to protect its core values, one of which is the protection of intellectual property.

The adoption of voluntary proactive measures by the individual online platforms is an example that illustrates how the Commission tries to react to the new challenges as regards the provision of protected subject-matter online, specifically it illustrates the "push" for the creation of self-regulative instruments by the online platforms themselves to ensure the protection of intellectual property rights. These mechanisms assist the online platforms which can than swiftly react when illegal content is identified and eliminate the need to take court action by the relevant rightholders, which spares both the time and costs of such litigation.

Moreover, the recently adopted proposal for the Directive on copyright in the Digital Single Market fundamentally challenges the existing liability regime as established in the eCommerce directive by effectively limiting its scope with the exclusion of the provision of a specific type of services from the applicable hosting exemption. The real application of this Directive in practice and issues related to it remain to be seen, however, it will definitely present a challenge not only for the subjects on which new obligations will be imposed, but also to the national law and courts required to interpret this new legislation.

58 See: Romero-Moreno, F., Notice and staydown and social media: amending Article 13 of the Proposed Directive on Copyright, International Review of Law, Computers \& Technology, 2019, p. 187-210

59 See: Senftleben, M. et al., The Recommendation on Measures to Safeguard Fundamental Rights and the Open Internet in the Framework of the EU Copyright Reform. European Intellectual Property Review, 2018, p. 149-163 


\section{REFERENCES}

\section{BOOKS AND ARTICLES}

1. Belleflamme, P.; Peitz, M., Digital piracy, Springer New York, 2014

2. Broder, A. Z., Some applications of Rabin's fingerprinting method, in: Sequences II. Springer, New York, NY, 1993. p. 143-152

3. Colangelo, G.; Maggiolino, M., ISPs' copyright liability in the EU digital single market strategy. International Journal of Law and Information Technology, Vol. 26, No. 2, 2018, p. 142-159.

4. Fredman, S., Making Equality Effective: The role of proactive measures, 2009

5. Frosio, G., To Filter, or Not to Filter? That is the Question in EU Copyright Reform. Research Paper No. 2017-16., 36 (2) Cardozo Arts \& Entertainment Law Journal, 2018, Centre for International Intellectual Property Studies (CEIPI), pp. 331-368

6. Frosio, G. F., From horizontal to vertical: an intermediary liability earthquake in Europe. Journal of Intellectual Property Law \& Practice, Vol. 12, No. 7, 2016, pp. 565-575

7. Frosio, G. F., Reforming intermediary liability in the platform economy: a European digital single market strategy. Nw. UL Rev. Online, 2017, p. 18

8. Gillespie, T., The Politics of 'Platforms', New Media \& Society, 2010, Vol. 12, No. 3, pp. 347-364.

9. Groom, J., The Pirate Bay: CJEU rules that operating a torrent file indexing site is a communication to the public, Journal of Intellectual Property Law \& Practice, Vol. 12, No. 12, 2017, p. $965-968$

10. Harrington, J., Information society services: information society services: what are they and how relevant is the definition? Computer Law \& Security Review, Vol. 17, No. 3, 2001, p. 174181

11. Jasserand, C., YouTube guilty but not liable for late removal of infringing material. Journal of Intellectual Property Law \& Practice, Vol. 7, No. 11, 2012, pp. 790-791

12. Letai, P., Is YouTube a copyright infringer? The liability of Internet hosting providers under Spanish Law, The Liability of Internet Hosting Providers Under Spanish Law, February 3, 2012, 2012

13. Marino, G., YouTube is not GEMA's main offender. Journal of Intellectual Property Law \& Practice, Vol. 7, No. 9, 2012, pp. 644-646

14. Eecke, P., Online Service Providers and Liability: A Plea for a Balanced Approach. Common Market Law Review, Vol. 48, Issue 5, 2011, pp. 1455, 1486-1487

15. Romero-Moreno, F., Notice and staydown and social media: amending Article 13 of the Proposed Directive on Copyright. International Review of Law, Computers \& Technology, 2019, p. $187-210$

16. Suchoža, J.; Hučková, R., Reflections on Arbitration Proceedings, in: The Relationship between Constitutional Values, Human Rights and Arbitration, New York: JurisNet, LLC, 2011, pp. 161-180

17. Verbiest, T.; Spindler, G.; Riccio, G. M., Study on the liability of internet intermediaries. Available at SSRN 2575069, 2007 
18. Wang, A. et al., An Industrial Strength Audio Search Algorithm, in: Ismir. 2003, p. 7-13

\section{COURT OF JUSTICE OF THE EUROPEAN UNION}

1. Case C-324/09 L'Oréal and Others [2011]

2. Joined cases C-236/08 to C-238/08 Google France and Google [2010]

3. Case C-306/05 SGAE [2006]

4. Case C-403/08 Football Association Premier League and Others [2011]

5. Case C-360/10 SABAM [2012]

6. Case C-70/10 Scarlet Extended [2011]

7. Case C-117/13 Technische Universität Darmstadt v Eugen Ulmer KG [2014]

8. Case C-312/14 Banif Plus Bank Zrt. v Márton Lantos and Mártonné Lantos [2015]

9. Case C-682/18 LF/Google LLC, YouTube Inc., YouTube LLC, Google Germany GmbH

10. Case C-683/18 Elsevier Inc./Cyando AG

11. Case C-325/14 SBS Belgium [2015]

12. Case C-527/15 Stiching Brein [2017]

13. Case C-610/15 Stiching Brein [2017]

\section{EU LAW}

1. Communication from the Commission to the European Parliament, the Council, the European Economic and Social Committee and the Committee of the Regions. A Digital Single Market Strategy for Europe. COM/2015/0192 final

2. Communication from the Commission to the European Parliament, the Council, the European Economic and Social Committee and the Committee of the Regions on the Mid-Term Review of the implementation of the Digital Single Market Strategy. A Connected Digital Single Market for All. COM (2017) 228 final

3. Communication from the Commission to the European Parliament, the Council, the European Economic and Social Committee and the Committee of the Regions Tackling Illegal Content Online Towards an enhanced responsibility of online platforms COM (2017) 555 final

4. Commission Recommendation of 1.3 .2018 on measures to effectively tackle illegal content online (C(2018) 1177 final)

5. Commission Staff Working Document Online Platforms Accompanying the document Communication on Online Platforms and the Digital Single Market. SWD/2016/0172 final

6. Directive 2000/31/EC of the European Parliament and of the Council of 8 June 2000 on certain legal aspects of information society services, in particular electronic commerce, in the Internal Market (Directive on electronic commerce) OJ L 178, 17.7.2000, p. 1-16

7. Directive 2001/29/EC of the European Parliament and of the Council of 22 May 2001 on the harmonisation of certain aspects of copyright and related right in the information society. OJ L 167, 22.6.2001, p. 10-19 
8. Directive (EU) 2015/1535 of the European Parliament and of the Council of 9 September 2015 laying down a procedure for the provision of information in the field of technical regulations and of rules in Information Society services (codification) OJ L 241, 17.9.2015, p. $1-15$

9. Proposal for a Directive of the European Parliament and of the Council on copyright in the Digital Single Market. COM/2016/0593 final - 2016/0280 (COD)

\section{WEBSITE REFERENCES}

1. Salman, A., YouTube by the Numbers: Stats, Demographics \& Fun Facts, [https://www.omnicoreagency.com/youtube-statistics] Accessed 27.03.2019

2. YouTube Content ID Service, 2018, [https://developers.google.com/apps-script/advanced/ youtube-content-id] Accessed 27.03.2019

3. Soundcloud, 2009, [https://soundcloud.com/] Accessed 27.03.2019

4. Zefr's right management, 2019, [https://zefr.com/about-us/rights-management] Accessed 27.03.2019 